CLINICAL STUDY

\title{
Ketoacidosis as the initial clinical condition in nine patients with acromegaly: a review of 860 cases at a single institute
}

\author{
Naohiro Yoshida $^{1}$, Hiromasa Goto ${ }^{1,4}$, Hisanori Suzuki ${ }^{1}$, Kaoru Nagasawa ${ }^{1}$, Akira Takeshita ${ }^{1,3}$, \\ Minoru Okubo ${ }^{1,3}$, Megumi Miyakawa ${ }^{1,3}$, Yasumichi Mori ${ }^{1,3}$, Noriaki Fukuhara ${ }^{2}$, Hiroshi Nishioka ${ }^{2,3}$, \\ Shozo Yamada ${ }^{2,3}$ and Yasuhiro Takeuchi ${ }^{1,3}$ \\ ${ }^{1}$ Division of Endocrinology and Metabolism and ${ }^{2}$ Hypothalamic and Pituitary Surgery, Toranomon Hospital, 2-2-2 Toranomon, Minato-ku, Tokyo \\ 105-8470, Japan, ${ }^{3}$ Okinaka Memorial Institute for Medical Research, Tokyo 105-8470, Japan and ${ }^{4}$ Department of Metabolism and Endocrinology, \\ Juntendo University Graduate School of Medicine, Tokyo 113-8421, Japan \\ (Correspondence should be addressed to Y Takeuchi at Toranomon Hospital Endocrine Center; Email: takeuchi-tky@umin.ac.jp)
}

\begin{abstract}
Objective: Excess GH causes insulin resistance and impaired glucose metabolism. The objective of this study was to clarify the prevalence of ketoacidosis as the initial presenting symptom of acromegaly. Design and methods: Data were collected from 860 patients with acromegaly who underwent pituitary surgery at Toranomon Hospital over the last 32 years, between 1980 and 2011.

Results: Nine cases had ketoacidosis before being diagnosed with acromegaly, including seven males and two females with a mean \pm s.D. age of $38.8 \pm 14.2$ years. Serum GH and IGF1 levels were $155 \pm$ $203 \mathrm{ng} / \mathrm{ml}$ and $9.86 \pm 0.68$ SDS before pituitary surgery and $3.6 \pm 1.7 \mathrm{ng} / \mathrm{ml}$ and $3.72 \pm 3.40$ SDS after surgery respectively. The maximum tumor diameter was $28.2 \pm 11.6 \mathrm{~mm}$ (ranging from 15 to $47 \mathrm{~mm}, n=8$ ). None of the patients were diagnosed with diabetes mellitus (DM) nor were they positive for antibodies related to type 1 DM. A possible precipitating factor for ketoacidosis in six cases was excessive ingestion of sugar-containing soft drinks. All the cases had invasive pituitary adenomas. After pituitary surgery, plasma glucose levels were under control without requiring insulin in all cases. Furthermore, six patients did not need oral hypoglycemic agents.

Conclusions: Approximately 1\% of patients with acromegaly presented with diabetic ketoacidosis as their first clinical condition.
\end{abstract}

European Journal of Endocrinology 169 127-132

\section{Introduction}

Acromegaly is characterized by autonomous secretion of GH, which is usually due to a pituitary somatotropic adenoma. $\mathrm{GH}$ stimulates synthesis and secretion of IGF1, especially in the liver (1). Diagnosis of acromegaly is usually delayed for years and leads to increased morbidity and mortality. Excess GH impairs metabolic regulation. Indeed, it is associated with hepatic and peripheral insulin resistance (2). Thus, patients with acromegaly are predisposed to developing diabetes mellitus (DM) in addition to skeletal complications and cardiovascular and respiratory diseases (3). Risk factors for impaired glucose metabolism include high serum levels of GH, older age, longer duration of the disease, family history of DM, and concomitant hypertension $(4,5,6)$. The prevalence of diabetes among patients with acromegaly has been reported to range from 19 to $56 \%(3)$.

Ketoacidosis is common among patients with type 1 DM. However, it is unusual for ketoacidosis to occur in patients with acromegaly in the absence of type $1 \mathrm{DM}$. Indeed, there are 18 cases of ketoacidosis complicated with acromegaly in the literature $(7,8,9,10,11,12$, $13,14,15,16,17,18,19,20,21,22,23)$. Only eight cases with ketoacidosis as the first clinical condition of acromegaly have been anecdotally reported $(13,14,15$, $16,17,19,20,21)$. The epidemiology and mechanism of ketoacidosis in acromegaly have not been elucidated. To address these issues, we reviewed 860 cases of acromegaly that were seen at Toranomon Hospital over the last 32 years. Here, we present nine cases that had ketoacidosis as a clinical condition before being diagnosed with acromegaly.

\section{Subjects and methods}

\section{Subjects}

We reviewed clinical data from 860 acromegaly patients who underwent pituitary surgeries at a single institute, Toranomon Hospital (Tokyo, Japan), consecutively from 1980 to 2011. Charts were reviewed according to the diagnosis and institutional registry data available at the time of pituitary surgery. 
We found nine cases whose first clinical condition was ketoacidosis before being diagnosed with acromegaly and evaluated their clinical characteristics. All data had been obtained from routine medical procedures and were collected retrospectively. This study was approved by the institutional review board at Toranomon Hospital. findings, elevated serum levels of GH and IGF1 after adenoma based on imaging studies. Although a $75 \mathrm{~g}$ oral glucose tolerance test (OGTT) is the standard performed before surgery in any of the present cases because sufficient hyperglycemia was present in the absence of glucose challenge. A transsphenoidal pituitary adenomectomy was performed on each patient by expert neurosurgeons. The presence of a GH-secreting pituitary adenoma was confirmed by immunohistochemistry in each case. Patients underwent the $75 \mathrm{~g}$ OGTT within 1 month of surgery.

\section{Laboratory tests and their analyses}

Immunoreactive insulin (IRI) was measured by a chemiluminescent enzyme immunoassay (LUMIPULSE Presto insulin, Fujirebio, Inc., Tokyo, Japan). Plasma glucose was measured by the hexokinase method (Liquitech Glucose HK Test, Roche Diagnostics Japan). Serum and urinary C-peptide concentrations were measured with commercially available kits as follows. We used the C-peptide kit 'Daiichi' (FUJIFILM RI Pharma Co. Ltd., Tokyo, Japan) until January 2003. The Chemilumi C-peptide kit (Siemens Healthcare Diagnostics K. K., Tokyo, Japan) was used until February 2007. The LUMIPULSE Presto C-peptide kit (Fujirebio, Inc.) was used thereafter. The sensitivity of each kit was at least $0.1 \mathrm{ng} / \mathrm{ml}$. The $\mathrm{CV}$ values of the intra- and interassays of each kit were $<10$ and $20 \%$ respectively. Serum GH was measured with commercially available kits as follows. The GH RIA kit (Abbot Japan Co. Ltd.) was used until August 1989. The HGH kit 'EIKEN' (EIKEN CHEMICAL Co. Ltd., Tokyo, Japan) was used until May 2001. The ST AIA-PACK HGH kit TOSOH (Tosoh Co., Tokyo, Japan) was used thereafter. Coefficients of correlation for C-peptide and GH were $0.990-0.994$ and $0.740-0.910$ respectively. IGF1 was measured with an IRMA (IGF1 IRMA Daiichi, TFB Co., Tokyo, Japan).

After surgery, all patients underwent a $75 \mathrm{~g}$ OGTT after an overnight fast. Blood samples were collected at baseline and 30, 60, 90, and $120 \mathrm{~min}$ after glucose ingestion. IRI, glucose, and GH were measured in blood samples. We used homeostatic model assessment (HOMA) computer software to estimate basal pancreatic $\beta$-cell function (HOMA- $\% \beta$ ) and insulin resistance (HOMA-IR) from fasting blood glucose and serum IRI levels $(24,25)$. Insulinogenic index is an OGTT-based
The diagnosis of acromegaly was based on clinical adjusting for age and sex, and the presence of pituitary diagnostic procedure for acromegaly, this test was not

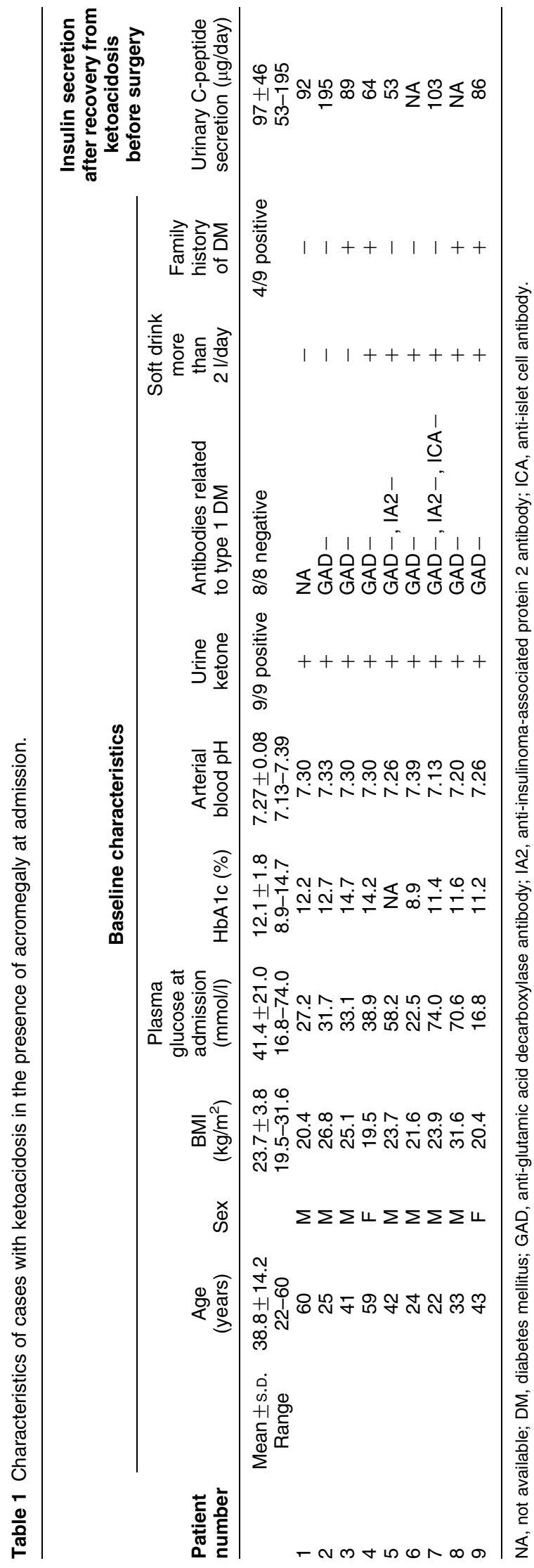

www.eje-online.org 
estimate of early-phase insulin secretion, which is calculated as (IRI at $30 \mathrm{~min}-\mathrm{IRI}$ at $0 \mathrm{~min}(\mu \mathrm{U} / \mathrm{ml})$ )/ (glucose at $30 \mathrm{~min}-$ glucose at $0 \mathrm{~min}(\mathrm{mg} / \mathrm{dl})$ ) (26).

\section{Statistical analysis}

Results are expressed as the mean \pm s.D. Student's $t$-tests or paired $t$-tests were applied to determine whether the differences between two groups were statistically significant $(P<0.05)$. Statistical analyses were done with SPSS version 16.0.2.

\section{Results}

Ketoacidosis was the first clinical condition in $\sim 1.0 \%$ of 860 consecutive cases of acromegaly. Table 1 shows the baseline characteristics of patients with ketoacidosis. Nine cases (seven males and two females) were diagnosed with ketoacidosis because they had low arterial blood $\mathrm{pH}$ values of $7.27 \pm 0.08$ and urinary ketones before being diagnosed with acromegaly. All patients with ketoacidosis had hyperglycemia $(41.4 \pm 21.0 \mathrm{mmol} / \mathrm{l})$ and high $\mathrm{HbAlc}(12.1 \pm 1.8 \%)$, suggesting the presence of diabetic ketoacidosis. However, none of the patients had histories of DM nor were they positive for antibodies related to type $1 \mathrm{DM}$. Overconsumption of alcohol was not reported for any of the subjects. The average age was $38.8 \pm 14.2$ years. This age was significantly younger than $48.2 \pm 13.4$ years, which was the average age for the other acromegaly patients $(P<0.05)$. Six patients had recent histories of excessive ingestion of sugar-containing soft drinks in quantities exceeding $2 \mathrm{l} /$ day (Table 1). Medical care was provided for ketoacidosis and hyperglycemia, and all patients were suspected of having acromegaly because of their appearance.

Parameters of intrinsic insulin secretion were evaluated after recovery from ketoacidosis but before pituitary surgery. The insulin secretion capacities were not depleted. The average urine C-peptide was $97 \pm 46 \mu \mathrm{g} /$ day (ranging from 53 to $195 \mu \mathrm{g} /$ day, $n=7$ ). The increase in serum C-peptide $10 \mathrm{~min}$ after an i.v. injection of $1 \mathrm{mg}$ glucagon was $3.0 \pm 0.6 \mathrm{ng} / \mathrm{ml}$ (ranging from 2.3 to $3.3 \mathrm{ng} / \mathrm{ml}, n=3$ ). At least one of the two parameters was examined in all nine cases.

Table 2 shows clinical data related to acromegaly before and after surgery. At the time of diagnosis, serum GH was $155 \pm 203 \mathrm{ng} / \mathrm{ml}$ and IGF1 was $982 \pm 98 \mathrm{ng} / \mathrm{ml}$ or $9.86 \pm 0.68$ SDS. The maximum tumor diameter was $28.2 \pm 11.6 \mathrm{~mm}$ (ranging from 15 to $47 \mathrm{~mm}, n=8$ ). Magnetic resonance imaging (MRI) was performed in all but one case of ketoacidosis. Images were not available for one of the earlier patients due to the absence of appropriate equipment. All the pituitary tumors that were visualized with MRI were macroadenomas with cavernous sinus invasion. Pituitary adenomas were totally resected in five cases

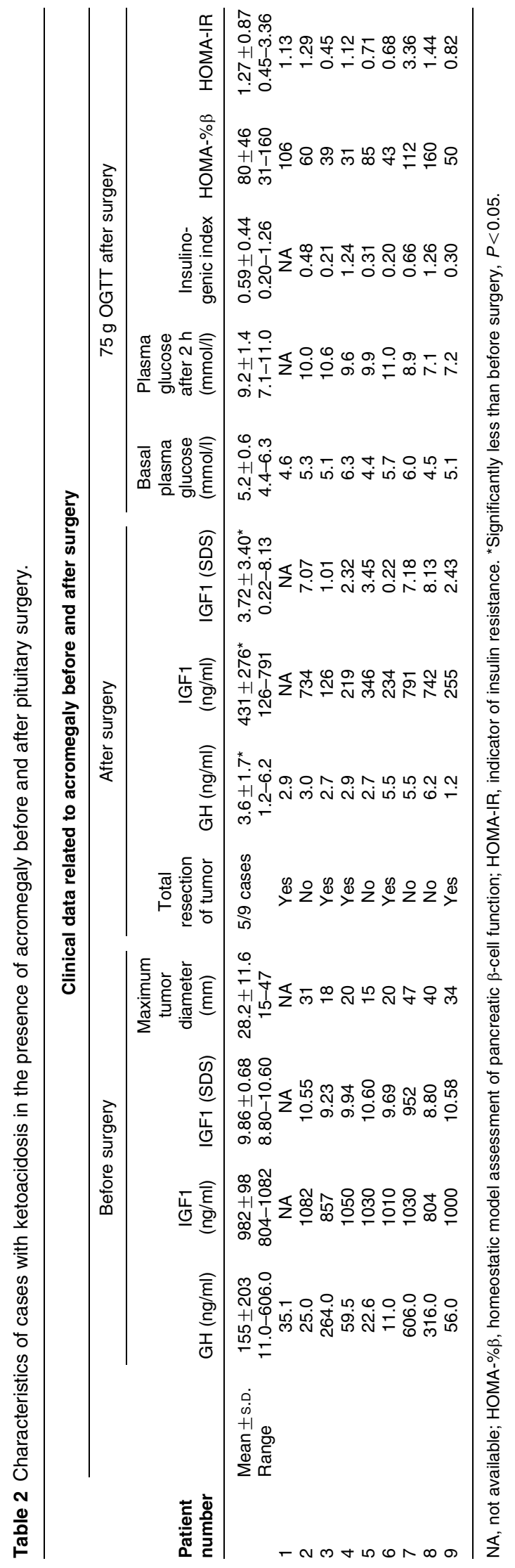

www.eje-online.org 
( $56 \%$ of cases). Residual tumors remained in the other four cases. Serum levels of GH were reduced after surgery in all cases (Table 2). The reduction from $155 \pm 203$ to $3.6 \pm 1.7 \mathrm{ng} / \mathrm{ml}$ was statistically significant (Table 2). Serum levels of IGF1 were also significantly reduced from $982 \pm 98 \mathrm{ng} / \mathrm{ml}(9.86 \pm 0.68 \mathrm{SDS})$ to $431 \pm 276 \mathrm{ng} / \mathrm{ml}(3.72 \pm 3.40$ SDS) (Table 2).

Plasma glucose levels were under control after surgery in all cases without requiring insulin therapy. Furthermore, six patients did not need oral hypoglycemic agents after surgery. Fasting plasma glucose levels at the time of the $75 \mathrm{~g} \mathrm{OGTT}$ were $<7 \mathrm{mmol} / \mathrm{l}$. Three cases were treated with metformin at either 500 or $750 \mathrm{mg} /$ day or with sitagliptin at $50 \mathrm{mg} /$ day. The insulinogenic index was $0.59 \pm 0.44(n=8)$, HOMA- $\% \beta$ was $80 \pm 46$, and HOMA-IR was $1.27 \pm 0.87$ (Table 2).

\section{Discussion}

We demonstrated that ketoacidosis was the first presenting clinical condition in $\sim 1 \%$ of patients with acromegaly in the absence of type $1 \mathrm{DM}$ or previously diagnosed type 2 DM. Thus, acromegaly should be considered when ketoacidosis presents in the presence or absence of type 2 DM. Four of nine cases with ketoacidosis had family histories of DM. Thus, regardless of the presence or absence of clinically apparent DM, in some cases, DM might be a precipitating factor for ketoacidosis in the presence of acromegaly, particularly because acromegaly usually exacerbates insulin resistance.

The average age of patients with ketoacidosis was significantly lower than that of other acromegaly patients. These observations are compatible with previous reports that young, male diabetic patients are more prone to developing ketoacidosis $(27,28)$.

Previous reports suggested that factors that promote ketoacidosis in acromegaly patients included infection, surgical procedures, cessation of octreotide, and excessive ingestion of sugar-containing soft drinks (21). In the present study, excessive ingestion of sugarcontaining soft drinks was a potential precipitating factor in six of nine cases. Patients with so-called soft drink ketosis are usually diagnosed because of negative anti-glutamic acid decarboxylase (GAD) antibodies, a history of excessive ingestion of carbohydrates including soft drinks, and obesity in the presence or absence of type 2 DM. Investigators have speculated that Japanese people are prone to soft drink ketosis because their maximum insulin secretion is not sufficient for the amount that is required for excessive consumption of sugar-containing soft drinks $(29,30,31)$. Kobayashi et al. (32) examined young patients with type 2 diabetes who presented with obesity and ketosis at the time of disease onset and found an impaired early-phase insulin response after glucose challenge. Those observations may also be true for Japanese patients who have acromegaly.
As we reported previously (33), normal glucose metabolism was restored in a subset of patients who underwent surgery for acromegaly. In that report (33), we divided acromegaly patients into three groups according to their glucose tolerance before and after surgery. Group I consisted of patients with normal glucose tolerance before surgery. Group II consisted of patients with impaired glucose tolerance before surgery and normal glucose tolerance after surgery. Group III included patients with impaired glucose tolerance before and after surgery. In the present study, the insulinogenic index, which measures early insulin secretion, was $0.59 \pm 0.44$. Further, HOMA- $\% \beta$, which is an index of basal insulin secretion, was $80 \pm 46$ after surgery in patients with histories of ketoacidosis. Both parameters were similar to those observed in postsurgical acromegaly subjects who had impaired glucose metabolism before surgery and normalized glucose metabolism following complete pituitary adenomectomy (33). Thus, intrinsic insulin secretion in the patients presented here seemed to be preserved after surgery. The insulinogenic index is usually calculated to assess the early-phase insulin response after glucose challenge (26). The insulinogenic index was decreased significantly in patients with acromegaly following successful treatment with somatostatin analogs (34). We could provide values for the insulinogenic index only after pituitary surgery. Those values were similar to data reported previously by Giordano et al. (34). $C$-peptide secretion after the standard mixed-meal tolerance test is another indicator of pancreatic $\beta$-cell function. This parameter was reported to be clinically relevant to metabolic derangement in patients with acromegaly (35). However, this information was not available for the present study.

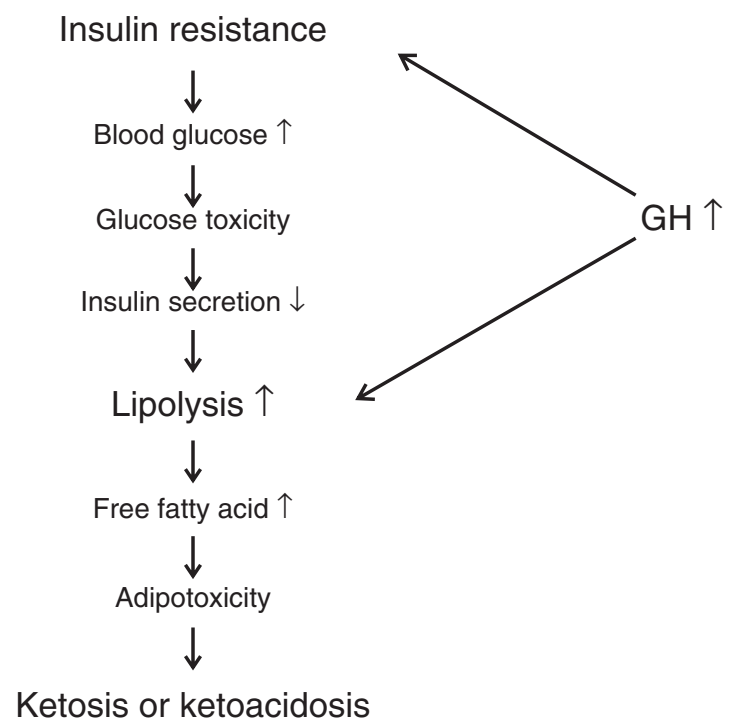

Figure 1 Schematic of the possible mechanisms by which metabolic derangement in acromegaly promotes development of ketoacidosis. 
As we reported, acromegaly exacerbates insulin resistance. However, some patients could not secrete sufficient insulin to overcome resistance (33). High plasma levels of glucose may reduce insulin secretion from $\beta$-cells, producing glucose toxicity. Excessive ingestion of soft drinks may further exacerbate glucose toxicity by impairing appropriate insulin secretion. Coexistence of acromegaly-associated insulin resistance and glucose toxicity due to overconsumption of soft drinks might be critical for the development of ketoacidosis due to deficient insulin action (Fig. 1). Enhancement of lipolysis by GH (36) is caused by loss of insulin activity, leading to increased ketone production by the Randle cycle. An increased level of ketones reduces insulin secretion, eventually leading to ketoacidosis. Thus, GH-mediated lipolysis may also be involved in the development of ketoacidosis in patients with acromegaly (Fig. 1).

In conclusion, our data indicate that $\sim 1 \%$ of patients with acromegaly present with ketoacidosis as their first clinical condition. Each of the nine cases discussed here had specific manifestations of acromegaly during initial treatment for ketoacidosis. These findings are clinically significant, as they call attention to the importance of diagnosing acromegaly early.

\section{Declaration of interest}

The authors declare that there is no conflict of interest that could be perceived as prejudicing the impartiality of the research reported.

\section{Funding}

The work was supported by a grant from Okinaka Memorial Institute for Medical Research (Y Takeuchi).

\section{References}

1 Ben-Shlomo A \& Melmed S. Acromegaly. Endocrinology and Metabolism Clinics of North America 200837 101-122, viii. (doi:10.1016/j.ecl.2007.10.002)

2 Møller N \& Jørgensen JO. Effects of growth hormone on glucose. lipid, and protein metabolism in human subjects. Endocrine Reviews 200930 152-177. (doi:10.1210/er.2008-0027)

3 Colao A, Ferone D, Marzullo P \& Lombardi G. Systemic complications of acromegaly: epidemiology, pathogenesis, and management. Endocrine Reviews 200425 102-152. (doi:10.1210/ er.2002-0022)

4 Resmini E, Minuto F, Colao A \& Ferone D. Secondary diabetes associated with principal endocrinopathies: the impact of new treatment modalities. Acta Diabetologia 200946 85-95. (doi:10.1007/s00592-009-0112-9)

5 Kreze A, Kreze-Spirova E \& Mikulecky M. Risk factors for glucose intolerance in active acromegaly. Brazilian Journal of Medical and Biological Research 200134 1429-1433. (doi:10.1590/ S0100-879X2001001100009)

6 Nabarro JD. Acromegaly. Clinical Endocrinology 198726 481-512. (doi:10.1111/j.1365-2265.1987.tb00805.x)

7 Ducobu J. Acromegaly and ketoacidosis. Acta Clinica Belgica 1990 $45282-283$.
8 Ma RC, Chow FC, Chung CC, Liu GC, Chan JC, Chan NN \& Cockram CS. Diabetic ketoacidosis in acromegaly: indication for long-term insulin therapy? International Journal of Clinical Practice 200256157.

9 Kuzuya T, Matsuda A, Sakamoto Y, Yamamoto K, Saito T \& Yoshida S. A case of pituitary gigantism who had two episodes of diabetic ketoacidosis followed by complete recovery of diabetes. Endocrinologia Japonica $1983 \quad 30 \quad 329-334 . \quad$ (doi:10.1507/ endocrj1954.30.329)

10 Katz JR, Edwards R, Khan M \& Conway GS. Acromegaly presenting with diabetic ketoacidosis. Postgraduate Medical Journal 199672 682-683. (doi:10.1136/pgmj.72.853.682)

11 Alvi NS \& Kirk JM. Pituitary gigantism causing diabetic ketoacidosis. Journal of Pediatric Endocrinology and Metabolism 199912 907-909. (doi:10.1515/JPEM.1999.12.6.907)

12 Kopff B, Mucha S, Wolffenbuttel BH \& Drzewoski J. Diabetic ketoacidosis in a patient with acromegaly. Medical Science Monitor 20017 142-147.

13 Vidal Cortada J, Conget Donlo JI, Navarro Téllez MP, Halperin Rabinovic I \& Vilardell Latorre E. Diabetic ketoacidosis as the first manifestation of acromegaly. Annales de Medecine Interne 199512 76-78.

14 Szeto CC, Li KY, Ko GT, Chow CC, Yeung VT, Chan JC \& Cockram CS. Acromegaly in a woman presenting with diabetic ketoacidosis and insulin resistance. International Journal of Clinical Practice 199751 476-477.

15 Erem C, Ersöz HO, Ukinç K, Avunduk AM, Hacihasanoglu A \& Koçak M. Acromegaly presenting with diabetic ketoacidosis, associated with retinitis pigmentosa and octreotide-induced bradycardia: a case report and a review of the literature. Endocrine 200630 145-149. (doi:10.1385/ENDO:30:1:145)

16 Lakhotia M, Mathur R, Singh H, Gahlot A, Tiwari V \& Gahlot RS. Diabetic ketosis as a presenting feature of acromegaly. Journal of Association of Physicians of India 200755 377-378.

17 Mewawalla P, Jaiswal G, Moustakakis M, Sankaranarayanan N \& Dasanu CA. Refractory DKA as first presentation of acromegaly and a potential role for continuous venovenous hemofiltration in its successful management. Connecticut Medicine 201175 405-407.

18 Chen YL, Wei CP, Lee CC \& Chang TC. Diabetic ketoacidosis in a patient with acromegaly. Journal of the Formosan Medical Association 2007106 788-791. (doi:10.1016/S0929-6646(08)60042-X)

19 Waterhouse M, Sabin I, Plowman N, Akker S \& Chowdhury T. A "growing cause" of diabetic ketoacidosis. BMJ Case Reports, 2009. (doi:10.1136/bcr.11.2008.1226)

20 Westphal SA. Concurrent diagnosis of acromegaly and diabetic ketoacidosis. Endocrine Practice 20006 450-452.

21 Abrahamson MJ. Death from diabetic ketoacidosis after cessation of octreotide in acromegaly. Lancet 1990336 318-319. (doi:10.1016/0140-6736(90)91859-9)

22 Ali O, Banerjee S, Kelly DF \& Lee PD. Management of type 2 diabetes mellitus associated with pituitary gigantism. Pituitary 200710 359-364. (doi:10.1007/s11102-007-0060-8)

23 Carrasco de la Fuente M, González-Albarrán O, Pérez López G \& Cano Megías M. Diabetic ketoacidosis as the first manifestation of a mixed growth hormone and prolactin-secreting tumor. Endocrinología y Nutrición $2010 \quad 57$ 507-509. (doi:10.1016/ j.endonu.2010.06.008)

24 Levy JC, Matthews DR \& Hermans MP. Correct homeostasis model assessment (HOMA) evaluation uses the computer program. Diabetes Care 199821 2191-2192. (doi:10.2337/diacare.21. 12.2191)

25 Wallace TM, Levy JC \& Matthews DR. Use and abuse of HOMA modeling. Diabetes Care 200427 1487-1495. (doi:10.2337/ diacare.27.6.1487)

26 Seltzer HS, Allen EW, Herron AL \& Brennan MT. Insulin secretion in response to glycemic stimulus: relation of delayed initial release to carbohydrate intolerance in mild diabetes mellitus. Journal of Clinical Investigation 196746 323-335. (doi:10.1172/ JCI105534) 
27 Kitabchi AE, Umpierrez GE, Miles JM \& Fisher JN. Hyperglycemic crises in adult patients with diabetes. Diabetes Care 200932 1335-1343. (doi:10.2337/dc09-9032)

28 Kitabchi AE, Umpierrez GE, Murphy MB, Barrett EJ, Kreisberg RA, Malone JI \& Wall BM. Management of hyperglycemic crises in patients with diabetes. Diabetes Care 200124 131-153. (doi:10.2337/diacare.24.1.131)

29 Yamada K \& Nonaka K. Diabetic ketoacidosis in young obese Japanese men. Diabetes Care 199619671.

30 Matsui J, Tamasawa N, Tanabe J, Kasai N, Murakami H, Matsuki K \& Suda T. Clinical characteristics of Japanese youth-onset type 2 diabetes with ketonuria. Diabetes Research and Clinical Practice 200570 235-238. (doi:10.1016/j.diabres.2005.03.037)

31 Tanaka K, Moriya T, Kanamori A \& Yajima Y. Analysis and a longterm follow up of ketosis-onset Japanese NIDDM patients. Diabetes Research and Clinical Practice 199944 137-146. (doi:10.1016/ S0168-8227(99)00023-6)

32 Kobayashi K, Amemiya S, Higashida K, Ishihara T, Sawanobori E, Mochizuki M, Kikuchi N, Tokuyama K \& Nakazawa S. Pathogenic factors of glucose intolerance in obese Japanese adolescents with type 2 diabetes. Metabolism 200049 186-191. (doi:10.1016/ S0026-0495(00)91221-6)

33 Kinoshita Y, Fujii H, Takeshita A, Taguchi M, Miyakawa M, Oyama K, Yamada S \& Takeuchi Y. Impaired glucose metabolism in Japanese patients with acromegaly is restored after successful pituitary surgery if pancreatic $\beta$-cell function is preserved. European Journal of Endocrinology 2011164 467-473. (doi:10.1530/EJE-10-1096)

34 Giordano C, Ciresi A, Amato MC, Pivonello R, Auriemma RS, Grasso LF, Galluzzo A \& Colao A. Clinical and metabolic effects of first-line treatment with somatostatin analogues or surgery in acromegaly: a retrospective and comparative study. Pituitary 201215 539-551. (doi:10.1007/s11102-011-0365-5)

35 Ciresi A, Amato MC, Pizzolanti G \& Giordano Galluzzo C. Visceral adiposity index is associated with insulin sensitivity and adipocytokine levels in newly diagnosed acromegalic patients. Journal of Clinical Endocrinology and Metabolism 201297 2907-2915. (doi:10.1210/jc.2012-1518)

36 Hansen TK, Gravholt CH, ØRskov H, Rasmussen MH, Christiansen JS \& Jørgensen JO. Dose dependency of the pharmacokinetics and acute lipolytic actions of growth hormone. Journal of Clinical Endocrinology and Metabolism 200287 4691-4698. (doi:10.1210/jc.2002-020563)

Received 20 January 2013

Revised version received 2 May 2013

Accepted 7 May 2013 